\title{
The Impact of Local Structures on Socio-Political Action; Case: Baluch in Iran
}

\section{ART ICLE INF O}

\section{Article Type}

Original Research

\section{Authors}

Zarqami B. ${ }^{1} P h D$

Roumina E.* $P h D$
How to cite this article

Zarqami B, Roumina E. The Impact of Local Structures on SocioPolitical Action; Case: Baluch in Iran. Geographical Researches Quarterly Journal.2018;33(3):24 -37 .

\section{A B S T R A C T}

Introduction and Background There is a relationship between local structures and individual and social actions. These relationships are formed before they are determined. These structures are not entirely objective frameworks. But some of them have merged with subjective characteristics. The studied structures in the Baloch region of Iran organize citizens' activities within a specific framework. The purpose of this article is to examine the impact of local and sustainable structures on Baluch political-social activities in Iran.

Aims The purpose of this article is to examine the impact of local and sustainable structures on Baloch political-social activities in Iran. Iranian Baluch has multi-layered local structures that shape these social-political actions.

Methodology The method of this research is descriptive-analytic. The research approach is mostly quantitative. The results are based on the logical reasoning of the results from the field study. In order to formulate the socio-political activities of the Baloch region of Iran, socio-political structures were first extracted through documentary and library study. Since the extracted structures did not have the required level of confidence, they were presented to the Baluchist experts in the form of research variables and refined and weighed based on the comments received. After weighing, the most important variables in the form of a researcher-made questionnaire were evaluated and then, after confirming validity and reliability, they were distributed among the target population.

Conclusion The results of field studies in the studied variables indicate the effect of these structures on the socio-political activities of Baluchis. Of the local structures, religion and related structures have a greater role. Also the national level plays a lesser role in Baluch social-political activities. Therefore, any kind of planning in relation to the citizens of this part of Iran needs to know about these structures and their sustainable effects on the actions of residents of this part of Iran. Keywords Baluch; Local Structure; Social Action; Political Action
*Department of Political Geography, Faculty of humanities, Tarbiat Modares University, Tehran, Iran ${ }^{1}$ Jahade Daneshgai University, Tehran Iran

\section{*Correspondence}

Address: NO. 330, Floor 3, Human Sciences Faculty, Tarbiat Modares University, Nasr Bridge, Jalal-Al-Ahmad Highway, Tehran, Iran.

Phone: -

Fax: -

e.roumina@modares.ac.ir

\section{Article History}

Received: July 16, 2018

Accepted: October 22, 2018

ePublished: December 09, 2018

\section{I T A T I O N L I N K S}

[Ahmadi; 2004] Ethnicity \& ethnocentrism ...; [Almond; 1956] Comparative ...; [Almond \& Coleman; 1960] The politics of the ...; [Azad Armaki; 1997] Theories of ...; [Azkia \& Ghaffari; 2005] Development ...; [Bashiriyeh; 2005] Marxist ...; [Bashiriyeh; 2010] Political ...; [Chilcote; 1998] Theories of comparative ...; [Craib; 2002] Modern social theory ...; [Dalby; 2008] Imperialism, domination, culture ...; [Dowse \& Hughes; 1972] Political ...; [Ebrahimbai Salami; 2005] The perspective of ...; [Ebrahimzadeh; 2010] Land use and ...; [Ebrahimzadeh; 2012] Geographical area of southeast ...; [Eckstein; 1988] A culturist theory ...; [Ghalibaf; 1996] Investigating of geographic ...; [Hafeznia \& Allahverdizade; 2010] A Study of Relationship between the Unitary ...; [Hafeznia \& Kaviani Rad;2004] The new ...; [Hajiani; 2010] Rreviewof ...; [Hatch; 1997] Organization theory ...; [Hosseini; 2008] Government policy ...; [Inglehart; 1988] The renaissance of ...; [Janebollahi; 1996] Political, social and economic ...; [Karimipour; 1992] Geopolitical analysis of crisis ...; [Kaviani Rad; 2001] The role of ethnic identity in ...; [Lashgari Tafreshi; 2018] An inquiry into the ... ; [Lazarsfeld; 1997] Insights and important ...; [Lerner \& Lucille; 2004] The passing of traditional ...; [Lijphart; 1980] The structure of inference ...; [Maghsoudi; 2001] Ethnic evolution in Iran ...; [Mirmohammadi; 2004] Discourses on national identity ...; [Moghadasi \& Ghodrati; 2004] The anthony giddens structural ...; [Nosratinejad; 2002] A survey on the political ...; [Papoli Yazdi;1988] Political-economic effects ...; [Razzaghi; 1996] Components of our political ...; [Rezaei; 2015] Impact of regional demands ...; [Ritzer; 1998] Contemporary sociological ...; [Salzman; 1996] Kin and contract in Baluch ...; [Sariolghalam; 2010] Political culture ...; [Weiner \& Huntington; 2002] Understanding political ...; [Zarghami; 2010] Comparative analysis of the ... 


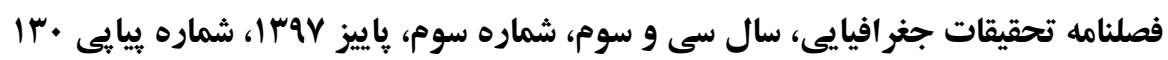

\section{تأثير ساختار هاى محلى بر كنش اجتماعى - سياسى؛ مورد: بلوجهاى ايران \\ دريافت مقاله:T}

DOI: 10.29252 /geores.33.3.24

جكيده

مقدمه: در اين ثيزوهش ساختار نه خارجوبى كاملاً عينيت يافته بلكه تا حدودى در آميخته با ذهنيت و تا حدودى توانايى

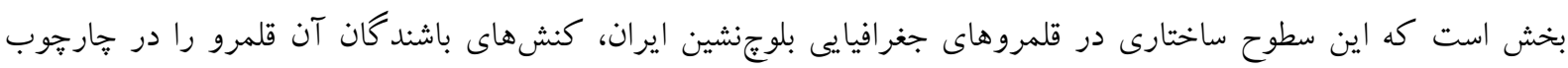
مشخصى سامان داده و يا جهتدهى مى كند.

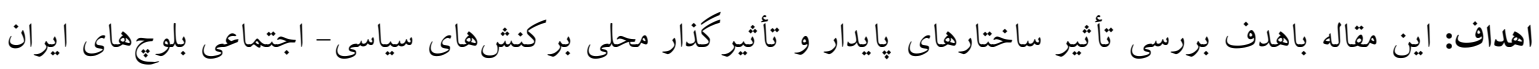
انجامشده است. ازنظر تئوريك بين اين ساختارها، روابطى ضرورى وجود دارد كه قبل از آنكه تعيين شوند تاندازهاى

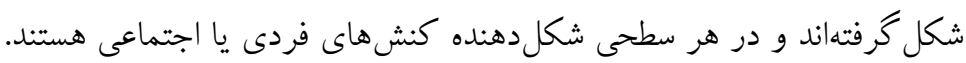

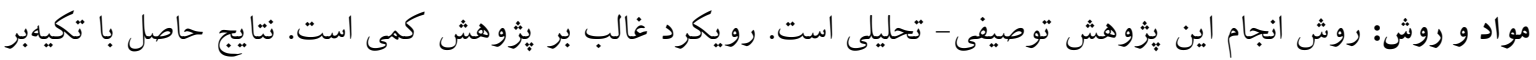
استدلال منطقى از نتايج حاصل از يافتهاى ميدانى استوار است. جهت احصاء كنشهاى اجتماعى - سياسى منطقه بلوتنشين

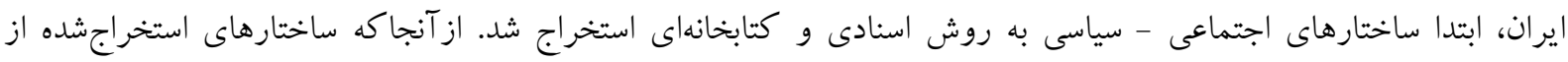

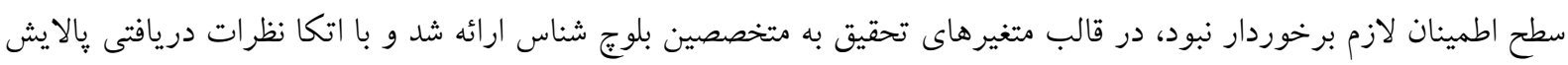

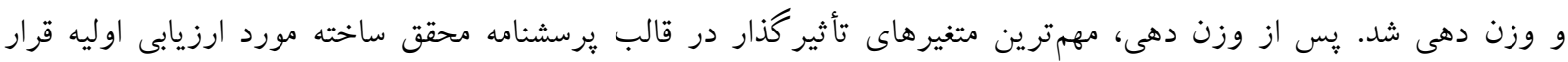

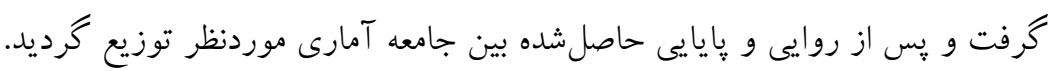

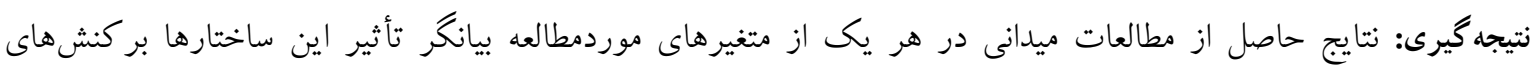

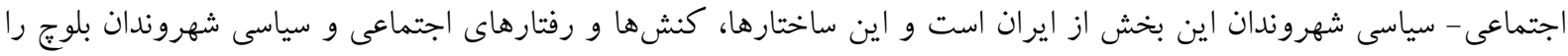
جهتدهى مى كند. لذا هر نوع برنامهريزى توسعهاى نيز در ارتباط با شهروندان اين بخش از ايران نيازمند شناخت اين ساختارها

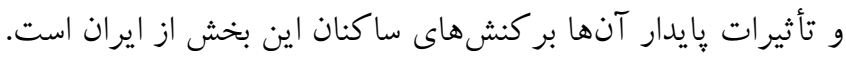

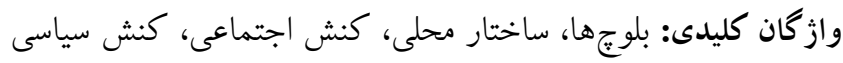

مقدمه

طيفى از خصلت ها، ويز گیىها، روحيات، ارزشها، ايستارها و احساسات، شهروندان فضاهاى جغرافيايى را از همديخر متمايز

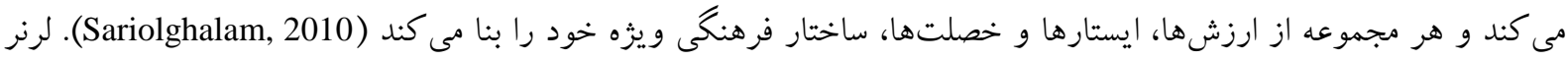

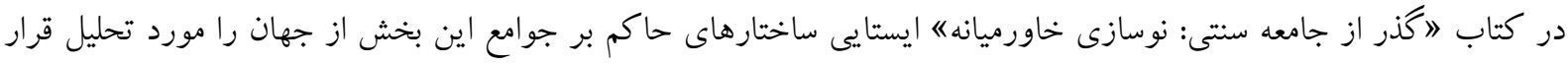

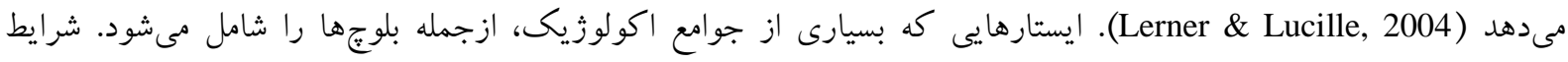




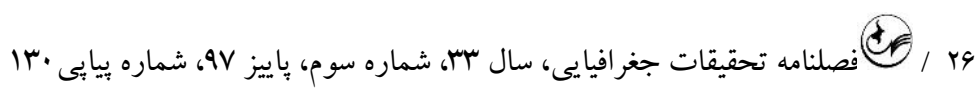
بلوجهاى ايران، همجون ديخر گروههاى اكولوزيك، ناشى از دلايل متعددى است كه يكى از اين دلايل، ساختارهاى حاكم بر

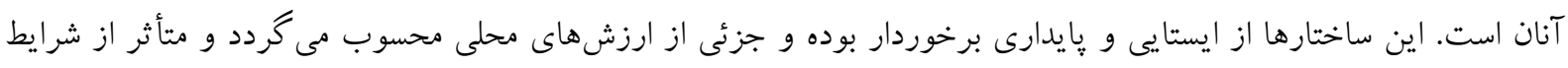

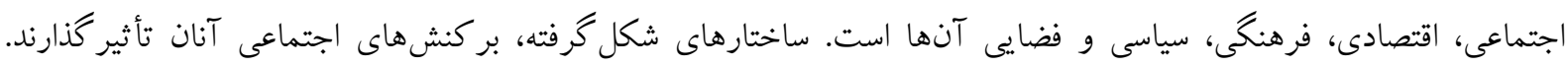

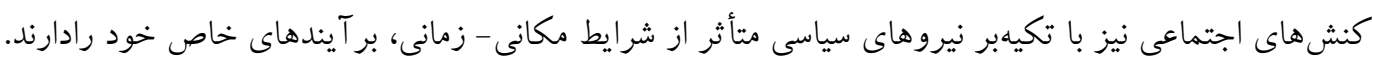

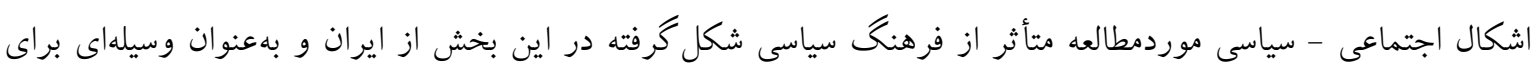

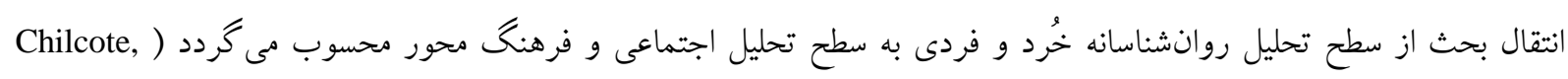

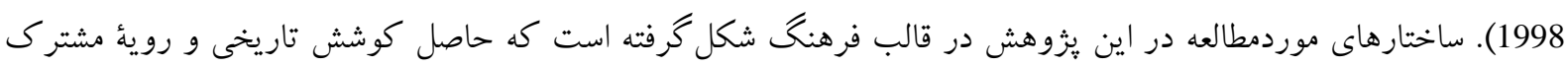

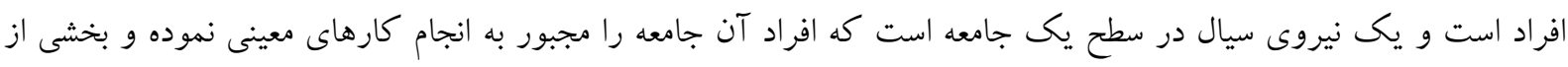

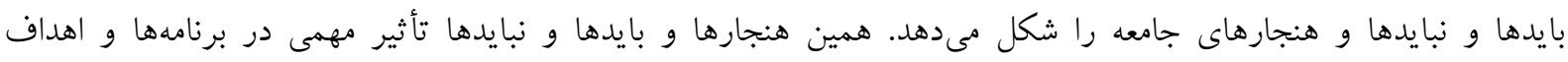

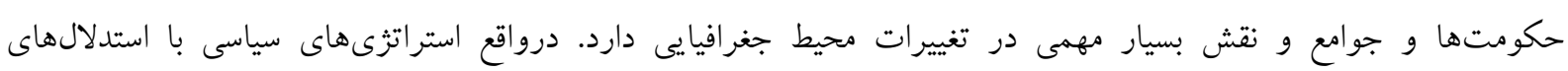

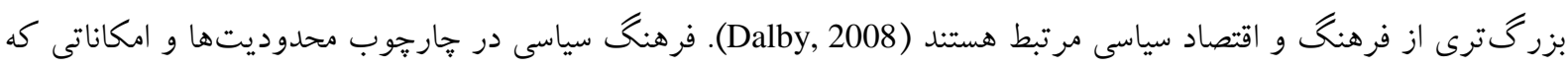

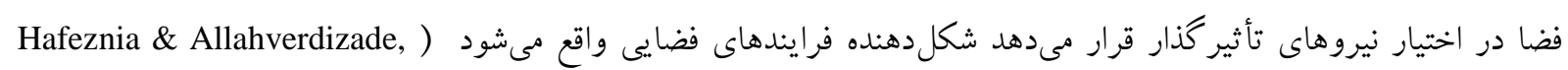

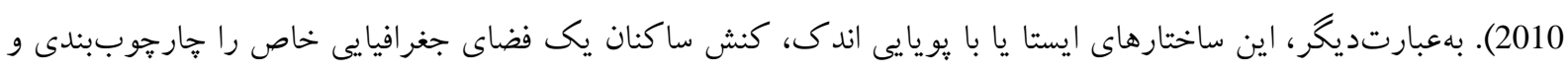

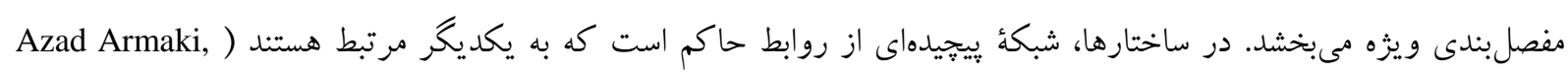
(1997; Craib, 2002

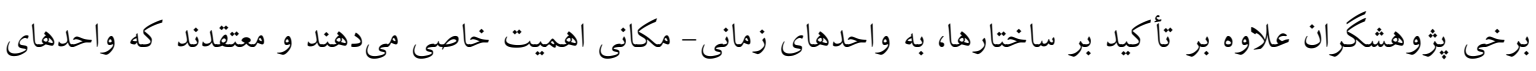

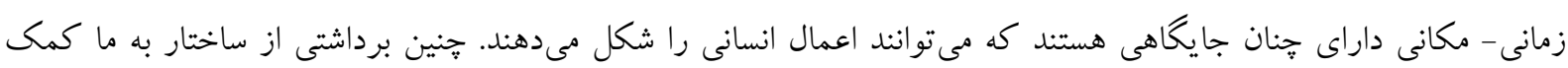

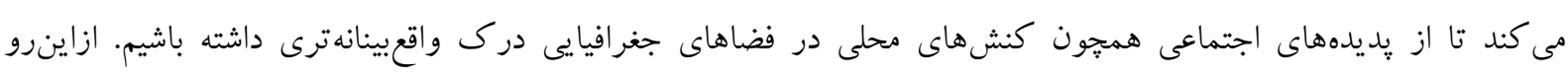
مفهوم فرهنگ سياسى بر مفروضات زير استوار است:

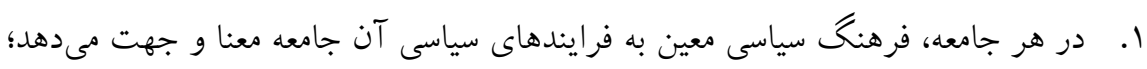

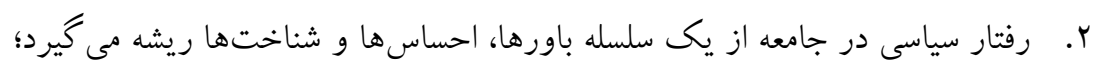

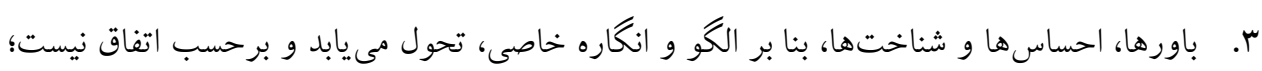

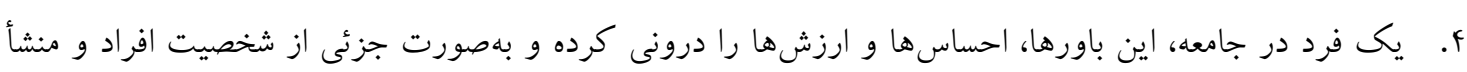

رفتار آنها درمى آيد (Razzaghi, 1996).

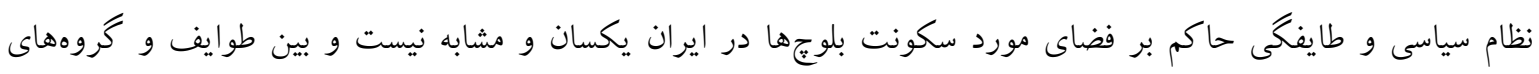

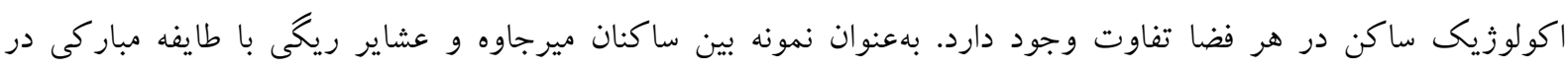

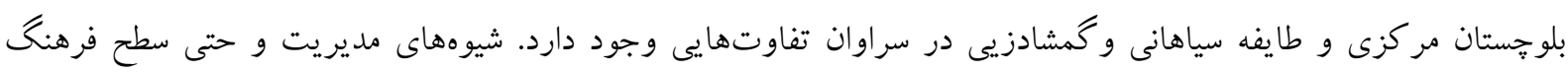

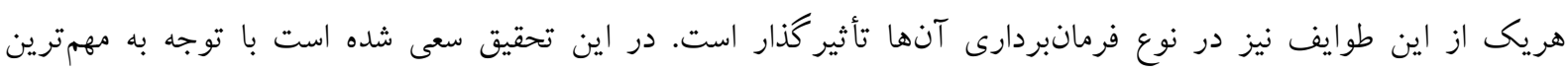

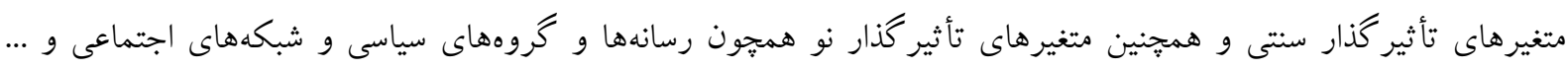

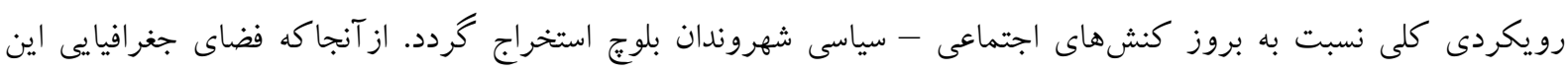

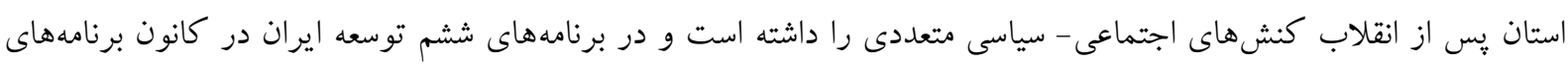

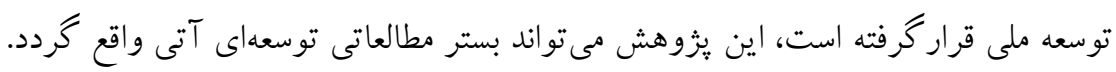




\section{روششنى تحقيق}

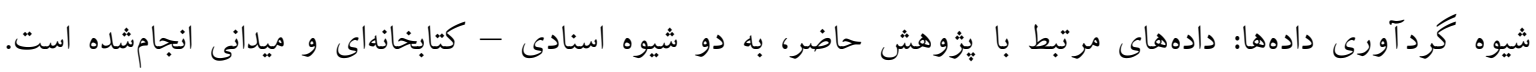

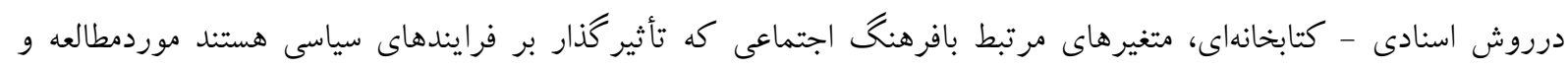

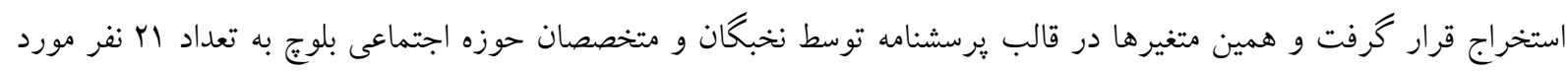

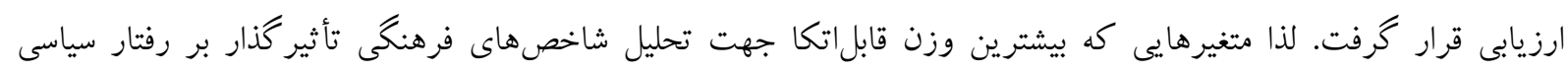

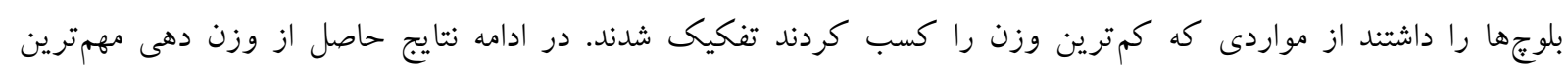

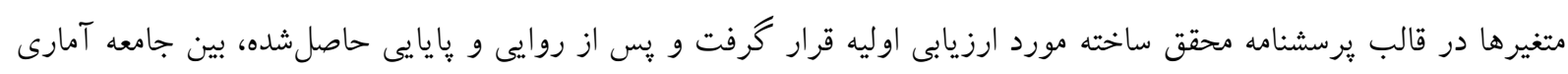

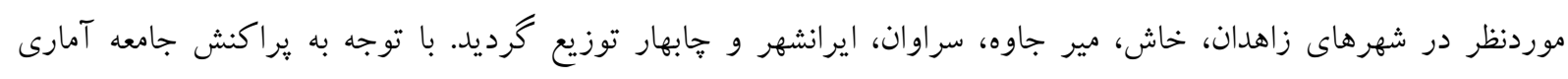

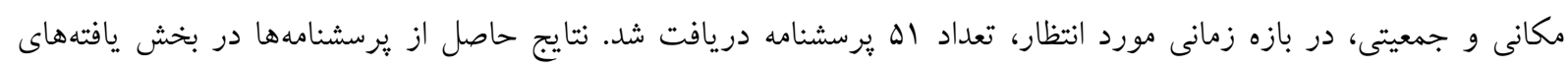

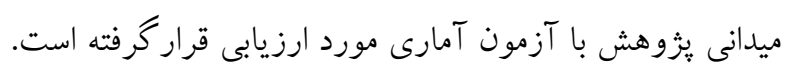

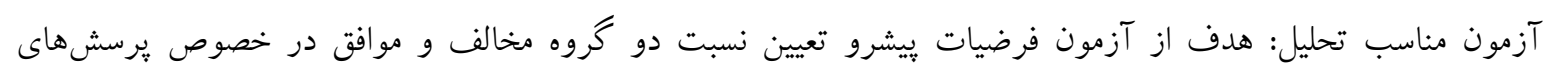

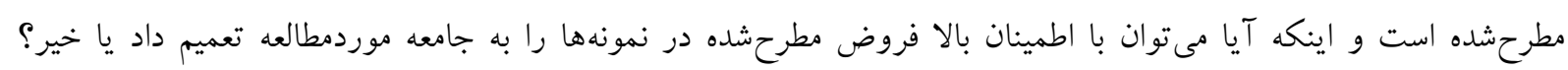

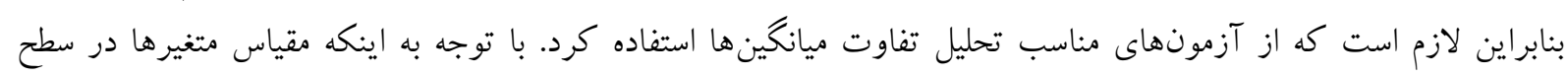

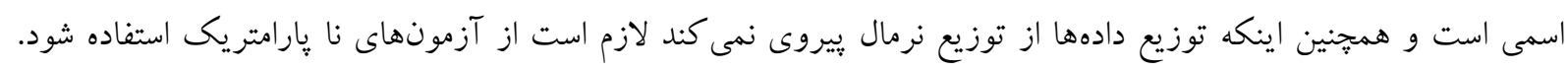

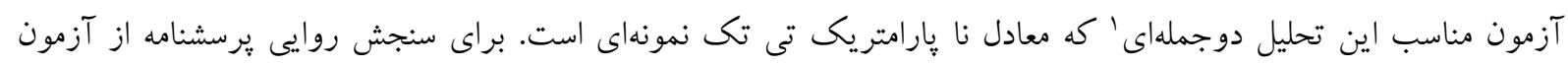

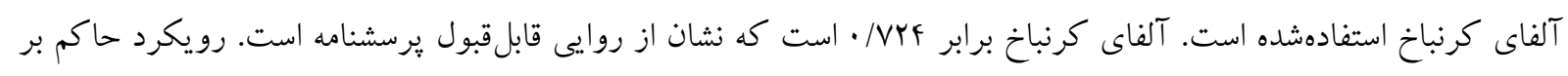

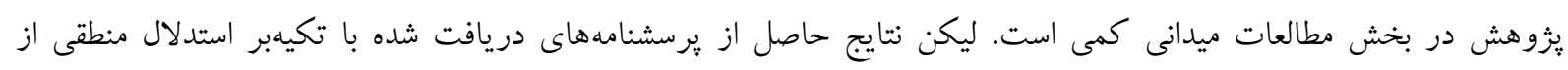
نتايج حاصل از يافتههاى ميدانى استوار است.

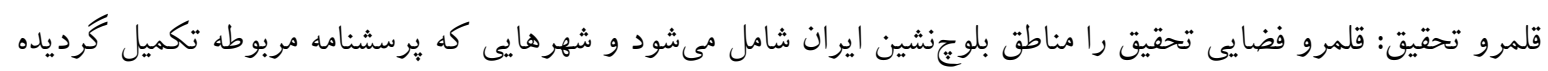

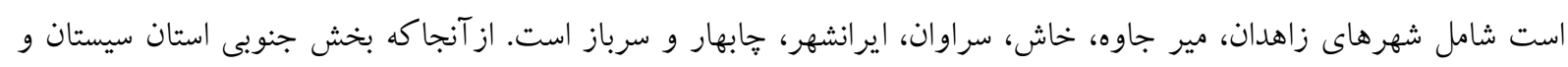

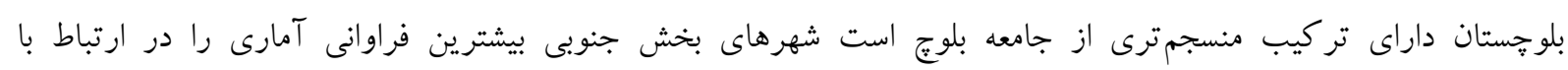

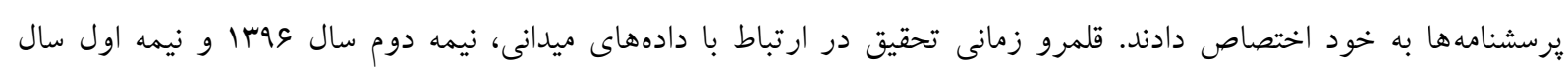

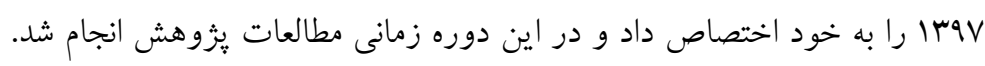

\section{جارجوب نظرى}

جارجوب نظرى اين يزوهش بر مبناى نظريه ساختارى است و فرهنگ سياسى بهعنوان بنمايه متغيرهاى موردمطالعه در بروز

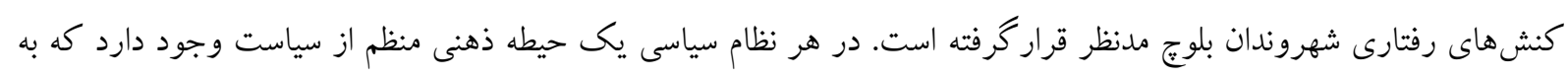

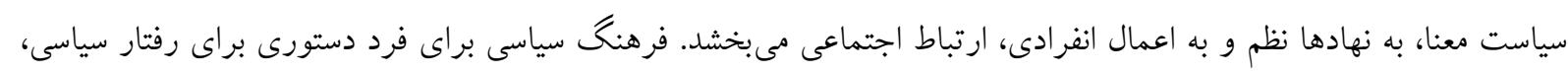

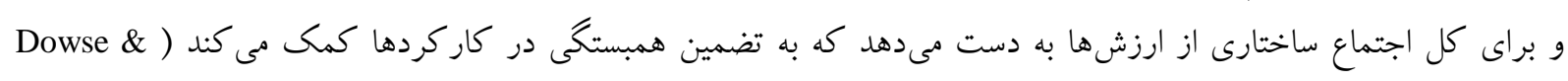

.(Hughes, 1972 اد گار شاين † فرهنگ را در تعامل سه لايه باورها و مفروضات، ارزشها و هنجارها و مفروضات و ساختهها موردبررسى قرار

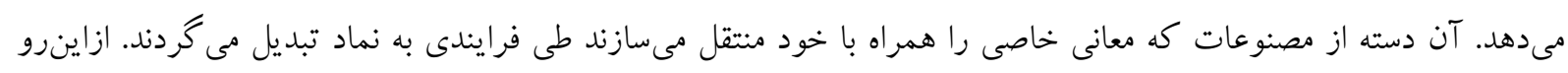

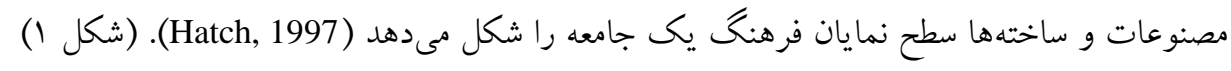




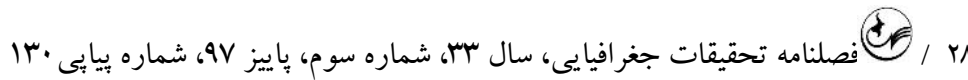

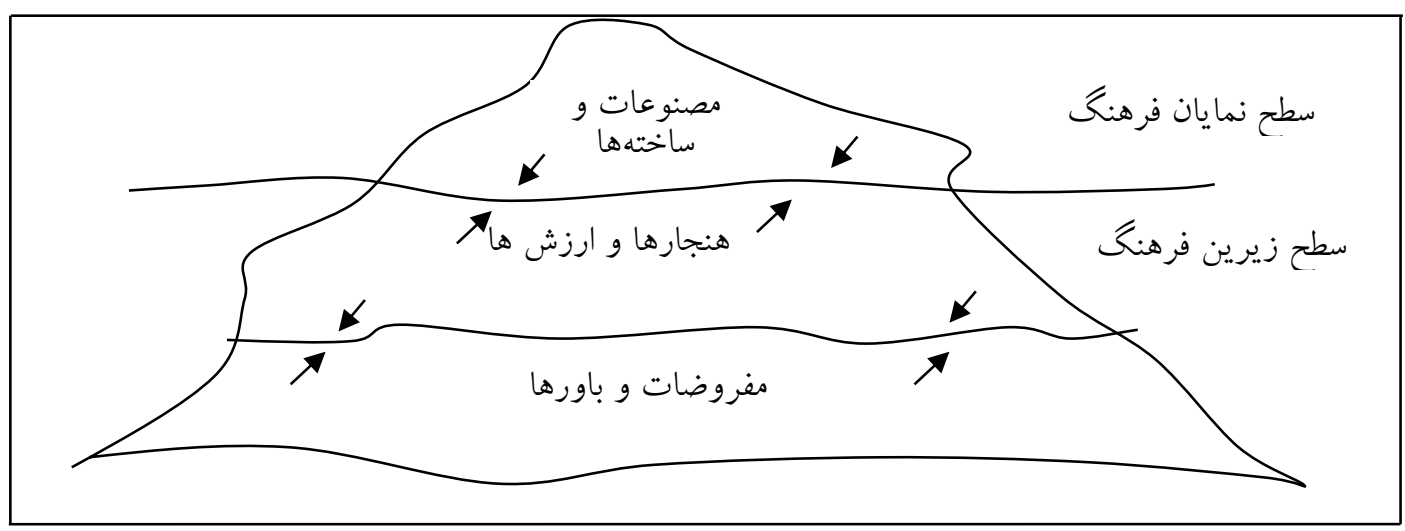

شكل 1 - سطح نمايان و زيرين فرهنك

منبع: (Hatch, 1997)

سيدنى وربا و ديخران، فرهنگ سياسى را در جارجوب غيرتجربى و در فرايند تاريخ بومى كشور مورد تأكيد قرار مىدهند Dowse \& ) و آنها در قالبهاى فرهنگ سياسى محدود؛ تابع يا انفعالى و مشاركتى تقسيمبندى مى كنند (Inglehart, 1988) (Hughes, 1972; Nosratinejad, 2002 بارنز، رابرت يوتنام و ديخران كه افراد و اعضاى يك جامعه با توجه به تصور و درك خود بدانها واكنش نشان مىدهند (Weiner \& Huntington, 2002)

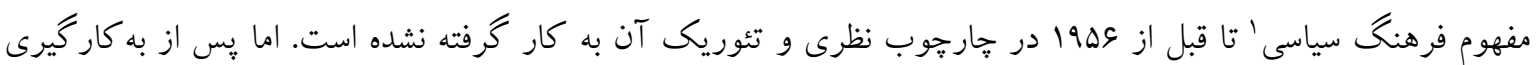
اين وازه در مقاله تحت عنوان انظامهاى تطبيقى سياسى" از سوى آلموند حوزه معرفتى كستردهاى يافت (Almond, 1956) و مفهومى كليدى در مقايسه و مطالعات تطبيقى و فرهنگى ميان كشورهاى جهان شد و توانست نقش برجستهاى را در تبيين رفتار

سياسى داشته باشد (Almond \& Coleman, 1960; Eckstein, 1988). نظرئه ساختارى شدن با نخاهى نو به ساختار و كنش، ضمن ارائه تعاريف جديدى از اين دو، آنها را درروند زندكى اجتماعى و يديدهاى طبيعى مؤثر مىداند (Ritzer, 1998). ساختار اجتماعى بهوسيله كنشخران فعال مورداستفاده قرار مى گيرد و خود همين ساختارها بهواسطه مشخصههاى ساختار و كنشخران متحول مىشود (Moghadasi \& Ghodrati, 2004) و عناصر يكى ساخت، تابع قواعد است و برحسب اين قواعد است كه ساخت مشخص مىشود (Bashiriyeh, 2005). در مركز نظريه ساختار، فرد بهعنوان كنشخر اجتماعى داراى خلاقيت، اختيار و نيروى ارزشيابى است. اما اين ارزشها و هنجارهاى اجتماعى است كه كنش وى را شكل مىدهد (Lazarsfeld, 1997) و شبكه ييجيدهاى از ارزشها، هنجارها، سنن و عادات اجتماعى در جامعه وجود دارند كه اراده انسانها را در خود محصور كرده و به آن جهت مىدهند. انسانها خارج از اين شبكه قادر به گزينش نبوده و تنها افعالى را انجام مىدهند كه در جارجّوب منافع عمومى است (Bashiriyeh, 2010; Craib, 2002). يارسونز فرهنگ را يكى از ابعاد جهار گانه جامعه (سياست، فرهنگ، اجتماع و اقتصاد) مىداند. وى فرهنخ را نظامى از كنش دانسته و متغيرهاى فرهنخ را نيز مطرح مى كند. به اين معنا كه دو گانكى فرهنگى را مطرح مى كند كه مدعى است برخى از گروهها يا افراد تنها يكى گونه آن رادارند. وى دو گانكى كنش عاطفى /كنش غير عاطفى؛ اشاعه / تفكيك؛ خاص كرايى / عام كرايى و انتساب و اكتساب را در ارتباط

بافرهنخ بيان مى كند (Azkia \& Ghaffari, 2005). فرهنگ سياسى مجموعهاى از تمايلات شناختى، تحليلى و احساسى است كه نسبت به يديدههاى سياسى ابراز مىشود

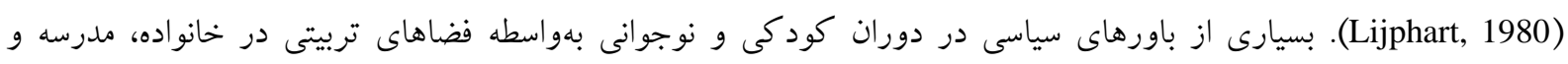


جامعه به فرد منتقل مى گردد و ثبات اين باورها و واقعى بودن نمادهاى آنها در جامعه باعث تكامل جامعه مىشود. تخنانجه

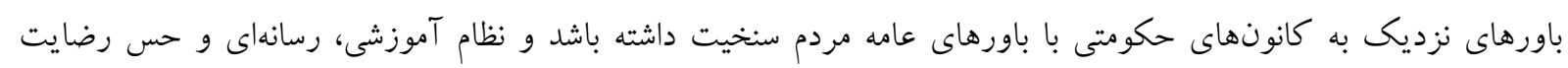

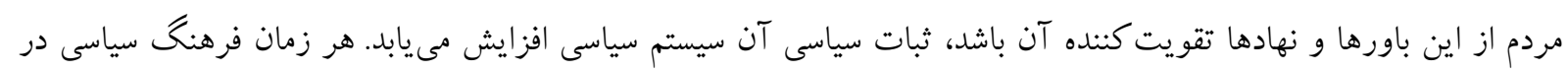

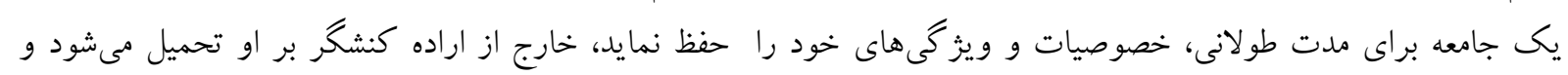
كار كرد آن منطق مسلط بر فرهنگ سياسى موجود را تبيين مى كند (Lashgari Tafreshi, 2018).

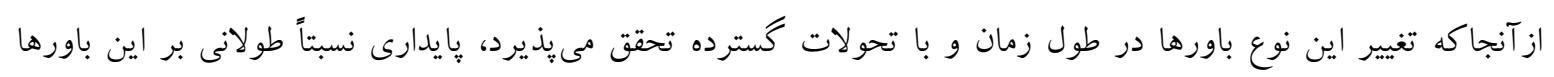

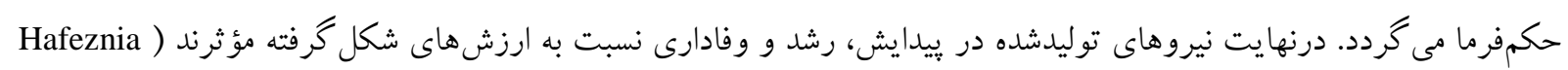

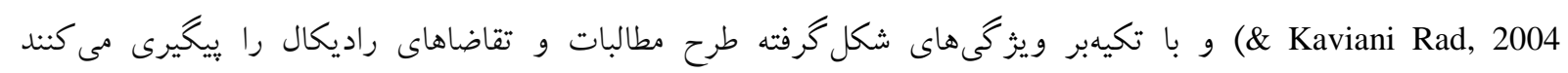

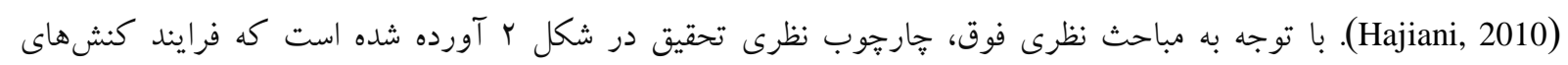

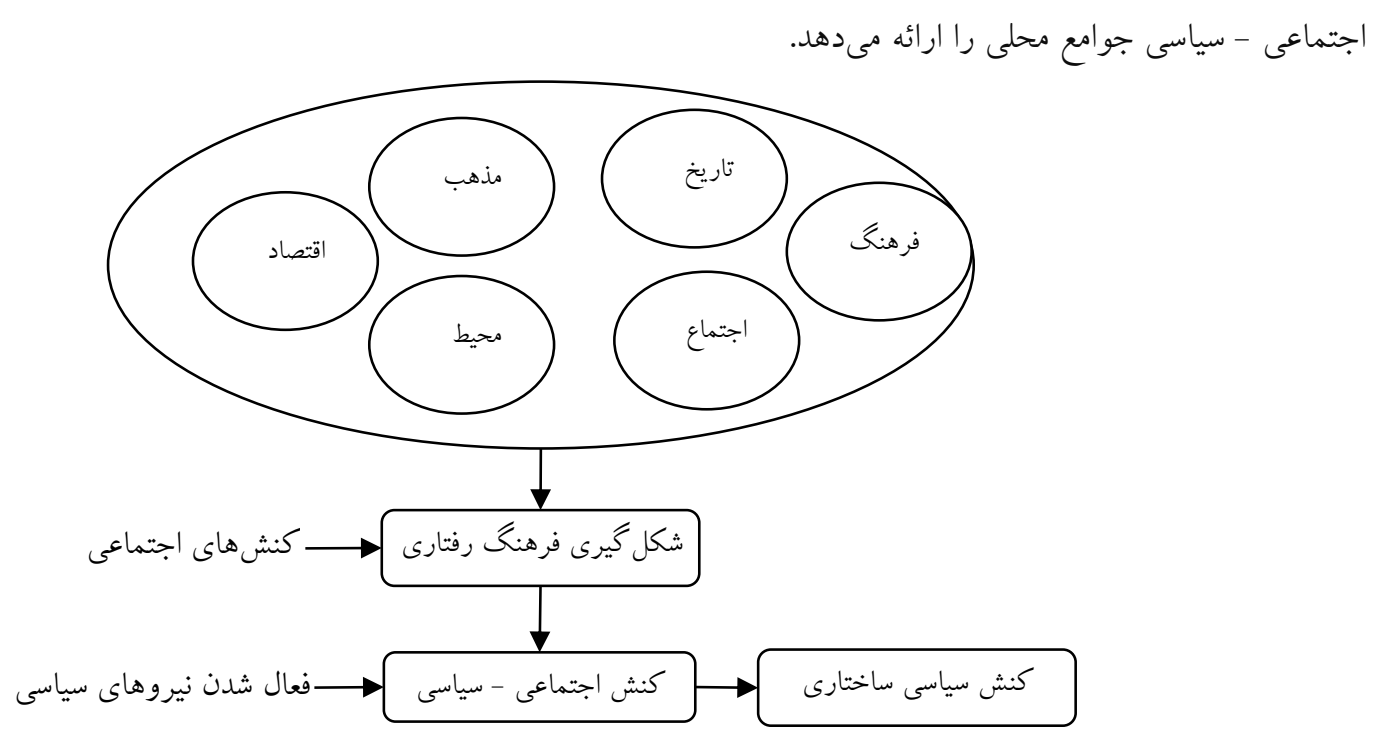

شكل r- فر آيند شكل كيرى كنشهاى اجتماعى - سياسى در جوامع محلى

بيشينه تحقيق

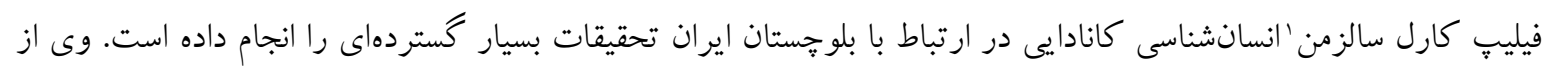

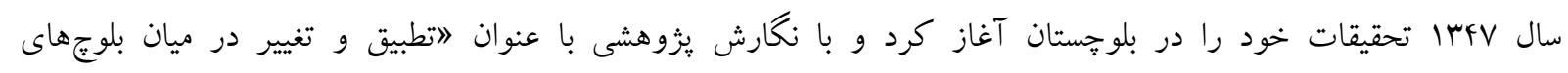

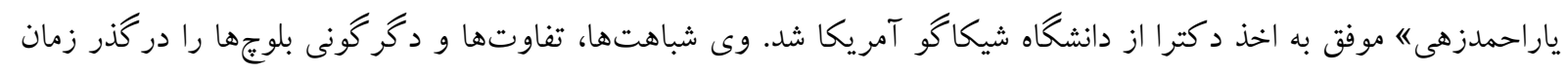

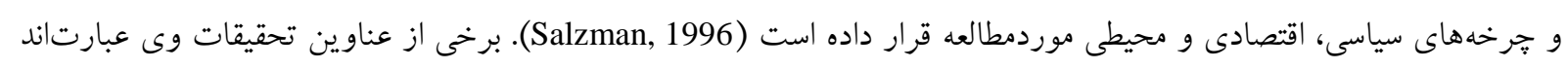

-

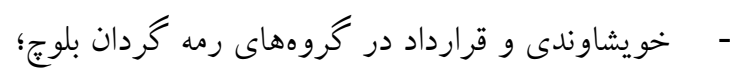
-

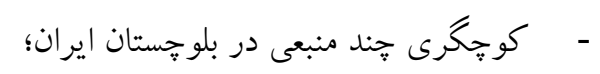
- - مباق و ساختار سياسى در بلوجستان ايران؛ - - اسلام و اقتدار در ايران قبائلى: يكى بررسى تطبيقى. 


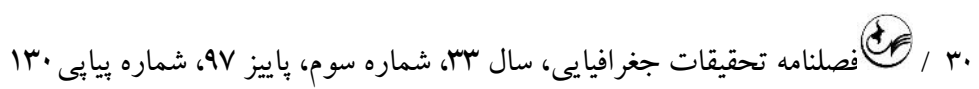

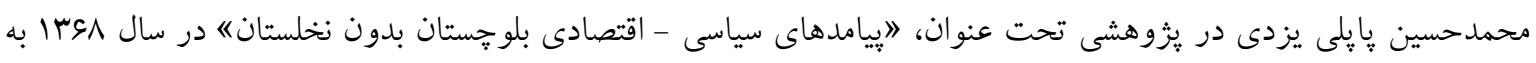

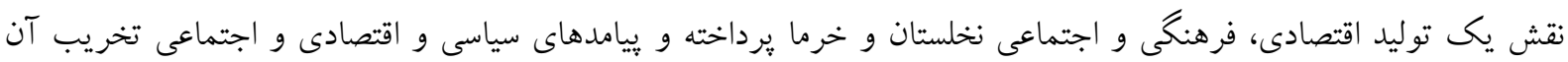

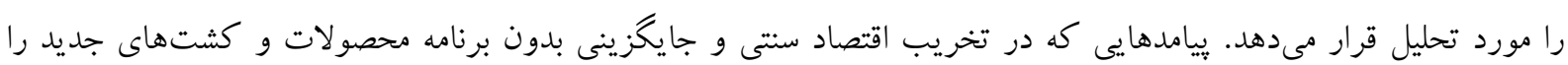

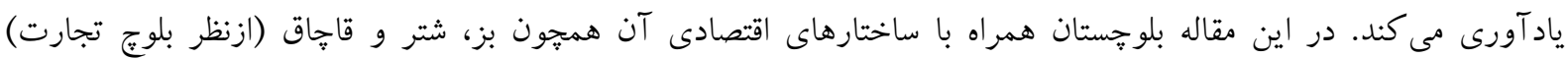

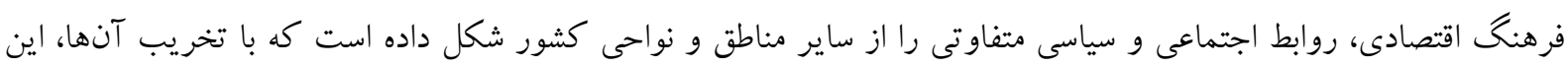

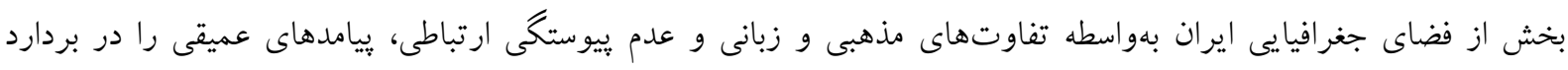

.(Papoli Yazdi, 1988)

غلام حيدر ابراهيمباى سلامى در مقاله "جشماندازهاى توسعه يايدار شرق ايرانه در فصلنامه تحقيقات جغرافيايى در سال

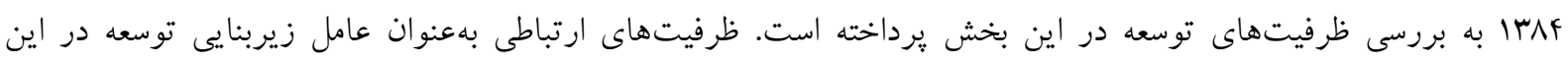

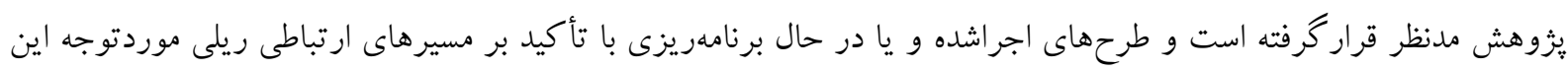

يخوهش بوده است (Ebrahimbai Salami, 2005).

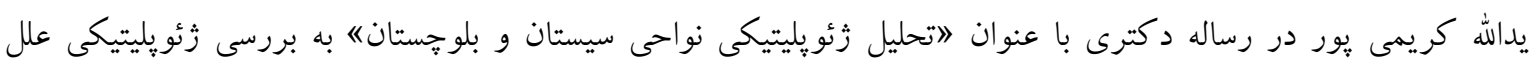

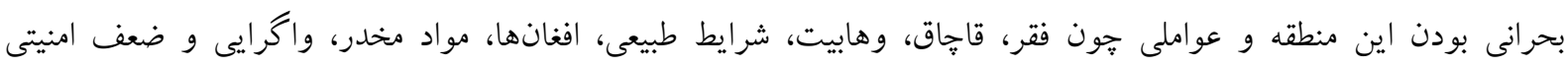
يرداخته است (Karimipour, 1992). محمد سعيد جانب اللهى در مقالهاى يثوهشى با عنوان انظامهاى سياسى، اجتماعى و اقتصادى در طوايف بلوج سرحد (نمونه:

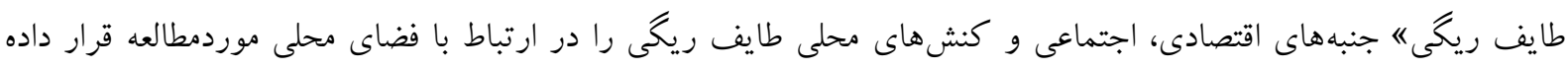

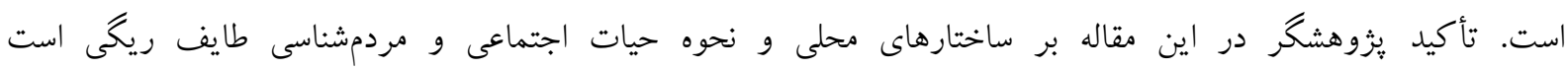
.(Janebollahi, 1996) مراد كاويانىراد در پاياننامه كارشناسى ارشد با عنوان "بررسى نقش قومى در اتحاد ملّى؛ مطالعه موردى قوم بلوجه" به

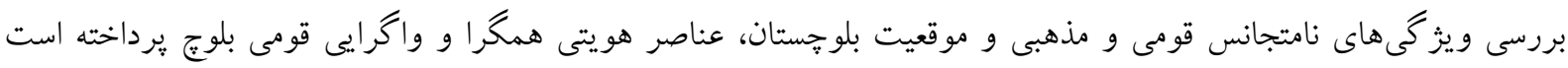

.(Kaviani Rad, 2001)

محمدباقر قاليباف در پاياننامه كارشناسى ارشد با عنوان البررسى و نقش عناصر جغرافيايى در امنيت سيستان و

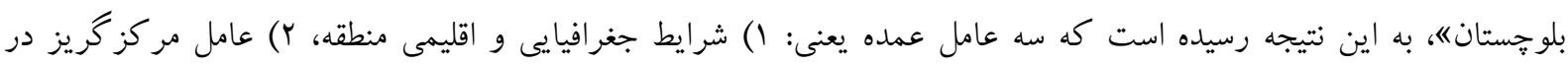

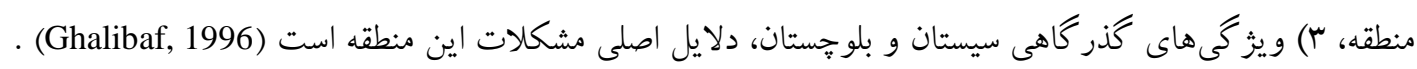

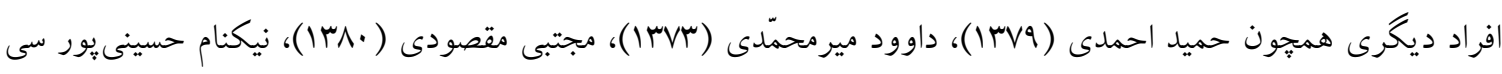

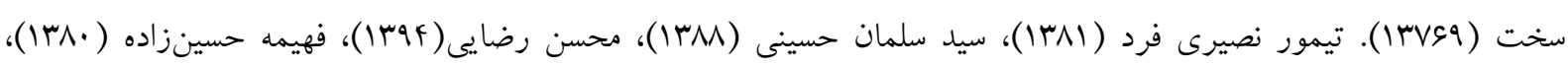

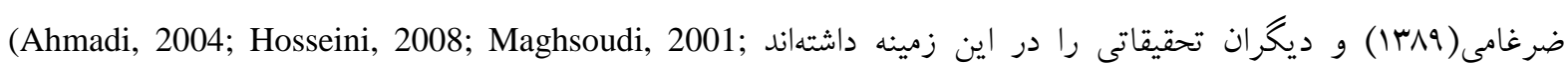
Mirmohammadi, 2004; Rezaei, 2015; Zarghami, 2010) 
از بين متغيرهاى استخراجشده در بخش كتابخانهاى، تعداد IV متغير كه تأثير كذار بر كنشهاى اجتماعى - سياسى بلوجهاى

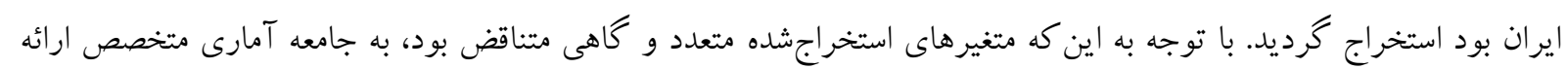

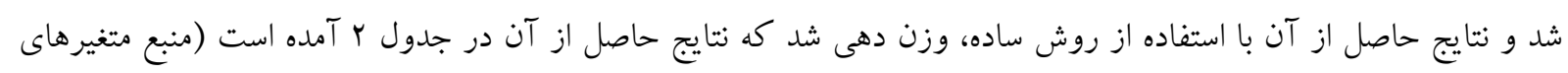

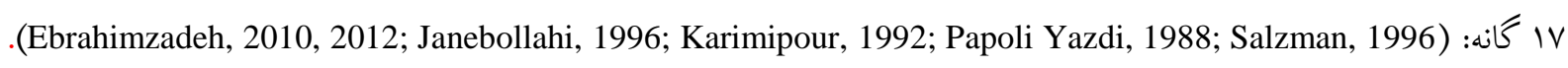
غالب متغيرهاى مورد تائيد، اجتماعى - فرهنكى بود كه بر مبناى مفروض اوليه، بر رفتار سياسى شهروندان تأثير گذارند.

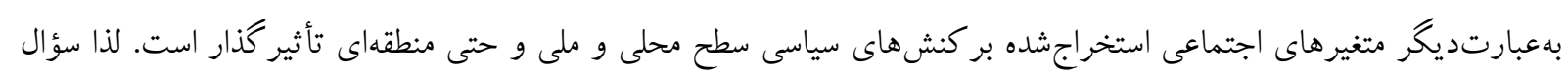

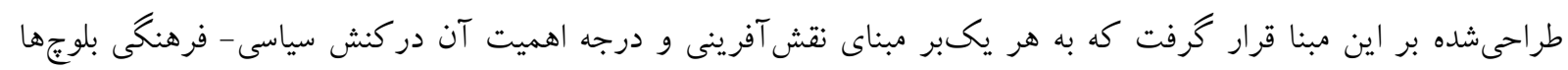

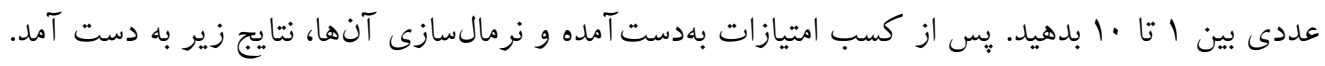

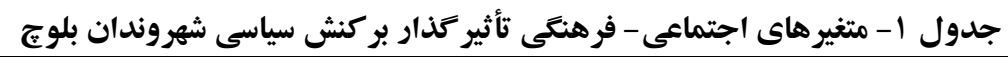

\begin{tabular}{|c|c|c|c|}
\hline 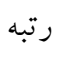 & ن رمالسازى & ميانگين نمره & 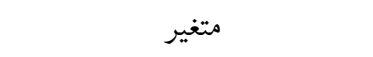 \\
\hline 1 & $\cdot|| r \mid$ & $s / s$ & رهبرى دينى و مذهبى \\
\hline f & $\cdot 11 \cdot 1$ & $\Delta / 9$ & ساختار طايفهاى \\
\hline$\Delta$ & $\cdot 11 \cdot 0$ & $\Delta / V Y$ & 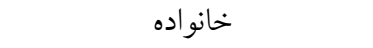 \\
\hline$\wedge$ &.$/ \cdot 9$ & $F / \Lambda \Lambda$ & رسانههاى دولتى \\
\hline V & $.1 \cdot 91$ & $f / 98$ & شبكههاى اجتماعى نوين \\
\hline s & $\cdot / \cdot 9 \mu$ & $\Delta / \cdot \wedge$ & فرد بهعنوان عضوى از قوم بلوج \\
\hline 1. & $\cdot 1 \cdot \mathrm{V}$ & $F / r r$ & ساختار سطح ملى \\
\hline 9 & $\cdot / \cdot \wedge s$ & $F / V$ & منافع فردى \\
\hline r & $\cdot / 1 \cdot 9$ & Q/9६ & آيين ها و رسمهاى محلى \\
\hline \multirow[t]{2}{*}{ r } &.$/ 118$ & $s / \mu_{F}$ & زبان بلوجى \\
\hline & 1 & $\Delta F / F G$ & جمع \\
\hline
\end{tabular}

يافته هاى برسشنامهاى

با توجه به تائيد متغيرهاى فرهنگ - اجتماعى تأثير گذار بر كنش سياسى شهروندان بلوج و تائيد روايى و هايايى حاصل از

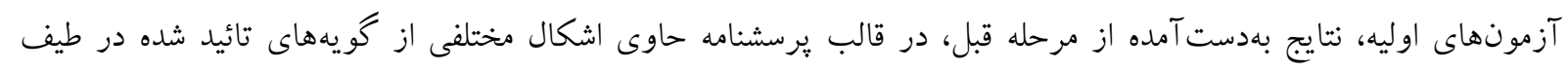

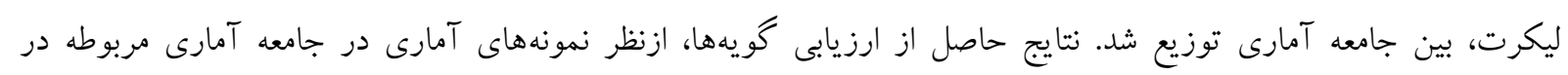
آزمون تى دوجملهاى به شرح جدول با بآمده است.

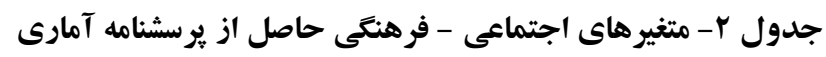

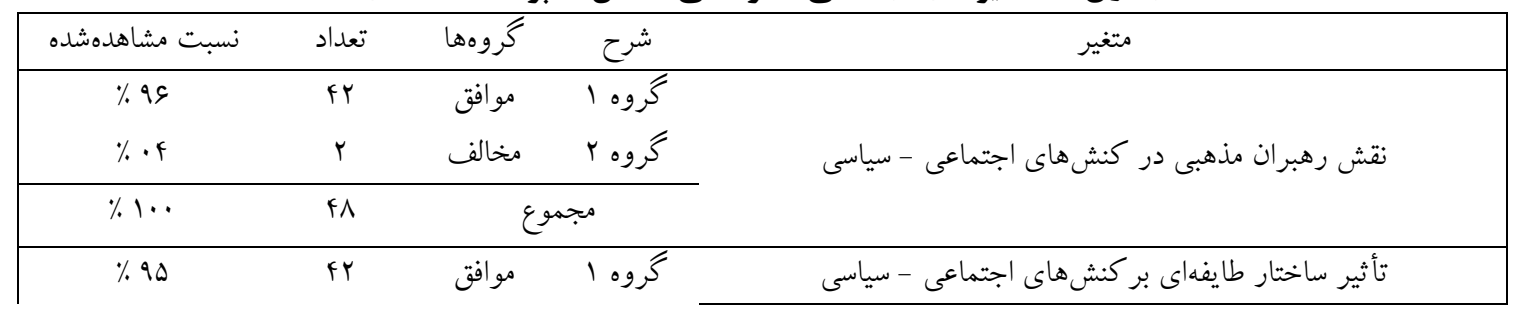




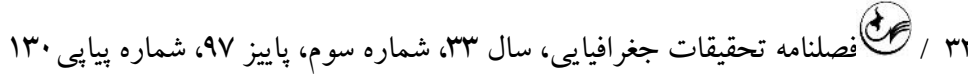

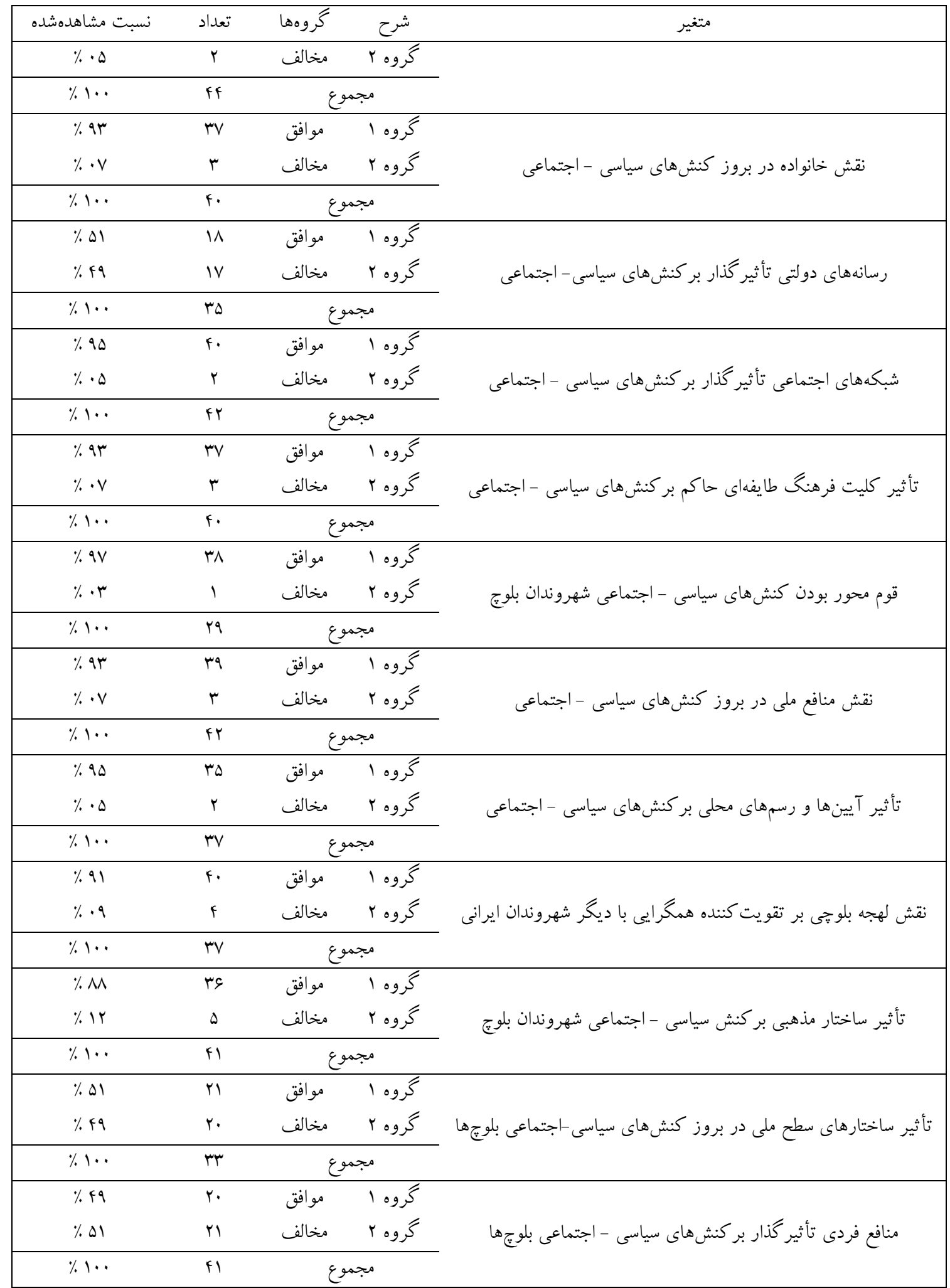

نقش رهبران مذهبى در كنشهاى اجتماعى - سياسى: با توجه به اينكه احتمال معنىدارى مشاهدهشده در اين گويه برابر

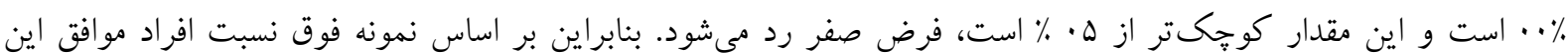
فرض كه "رهبرى دينى و مذهبى ترغيب كننده كنشهاى سياسى - اجتماعى" است، برابر عq درصد است. درنتيجه فرضيه موردنظر تائيد مىشود. 
تأثير ساختارهاى محلى بر كنش اجتماعى - سياسى مورد: بلوجهاى ايران / بr

تأثير ساختار طايفهاى بركنشهاى اجتماعى - سياسى: در ارتباط با ساختار طايفهاى تأثير كذار بر كنشهاى اجتماعى -

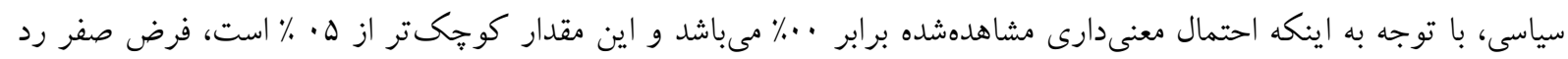

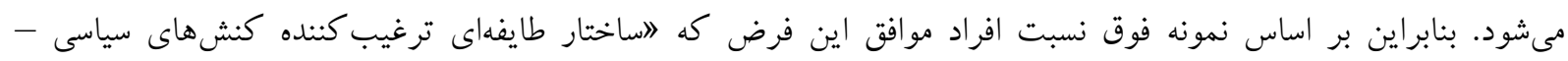

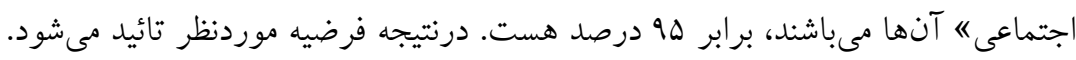

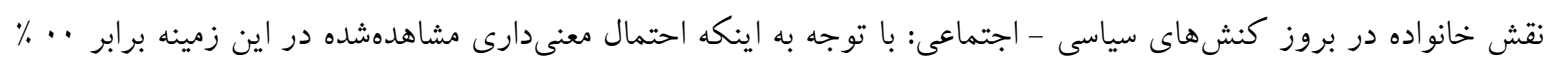

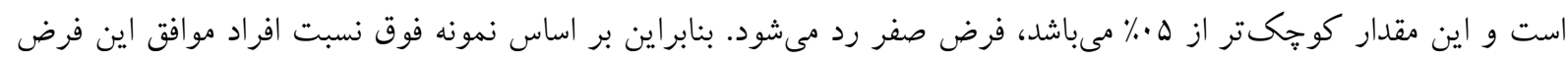

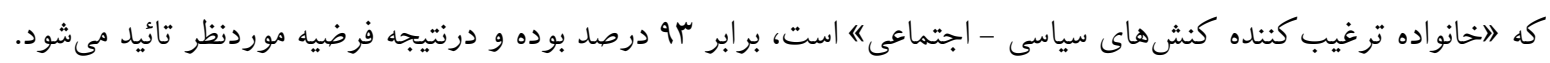

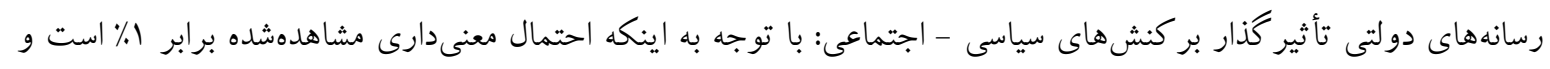

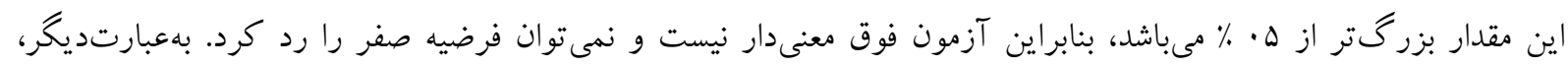

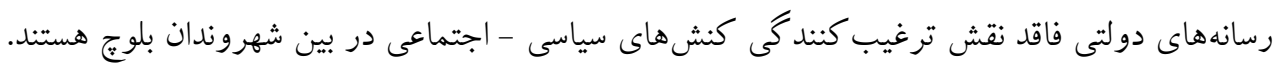

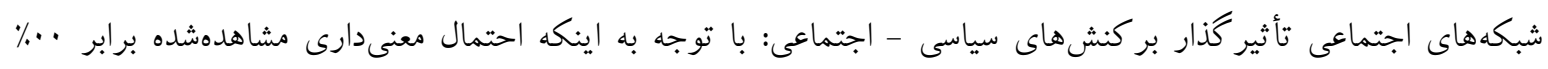

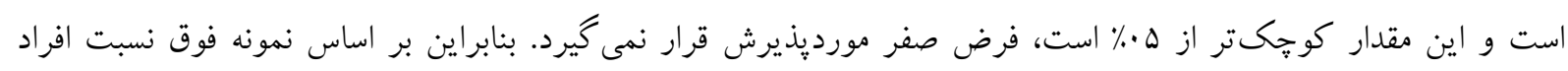

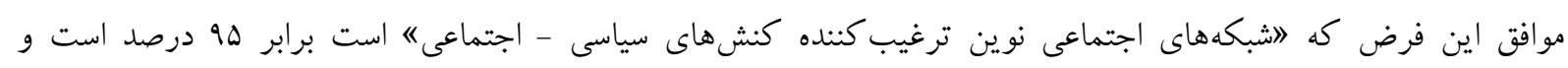
درنتيجه فرضيه موردنظر تائيد مى إنود.

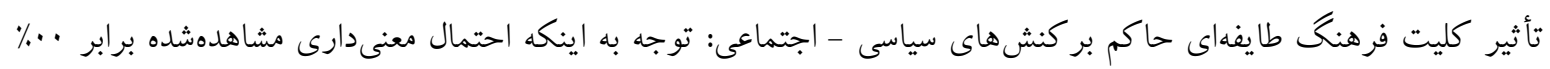

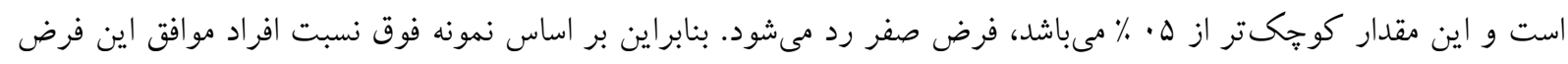

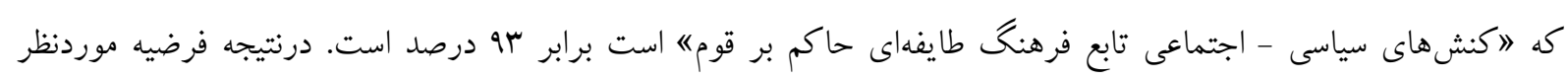
تائيد مىشود.

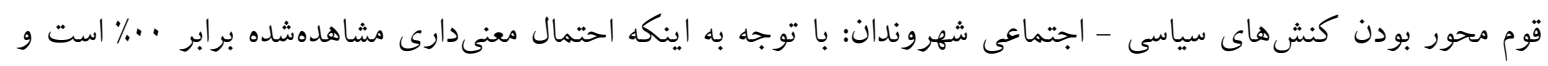

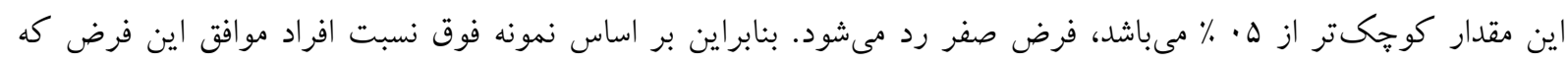

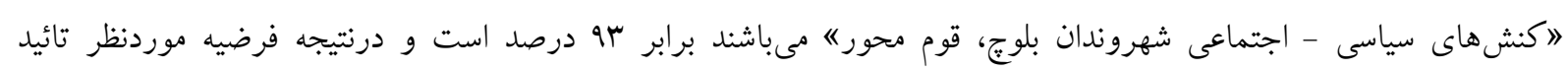
مىشود.

نقش منافع ملى در بروز كنشهاى سياسى - اجتماعى: با توجه به اينكه احتمال معنىدارى مشاهدهشده برابر ..٪ است و اين

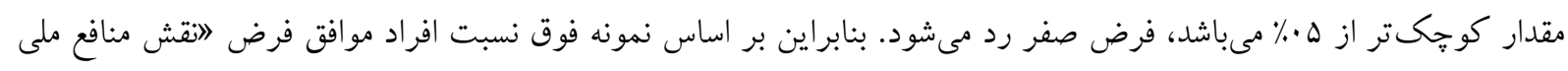

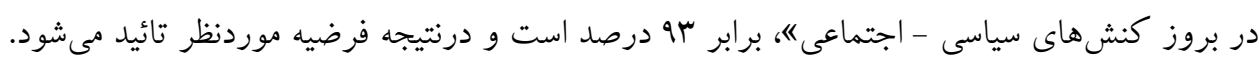

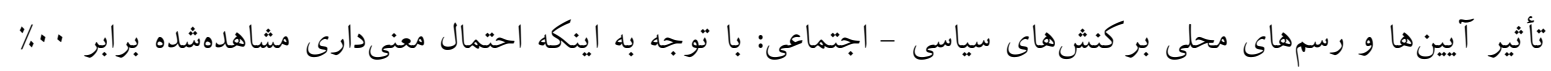

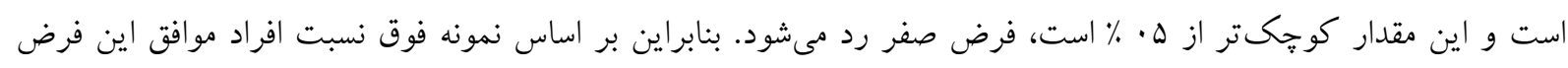

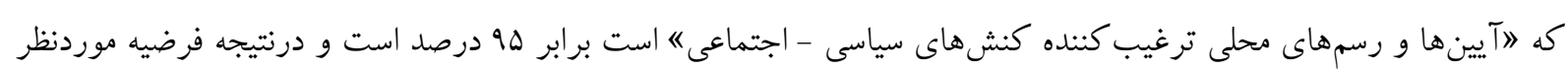
تائيد مىشود.

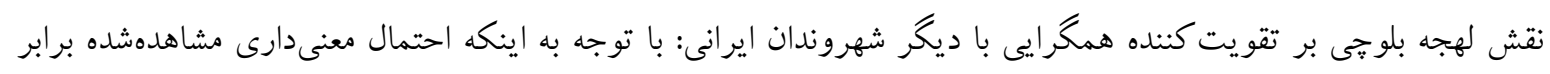

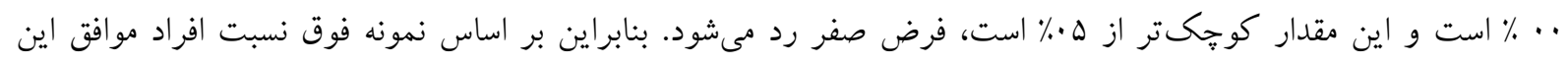

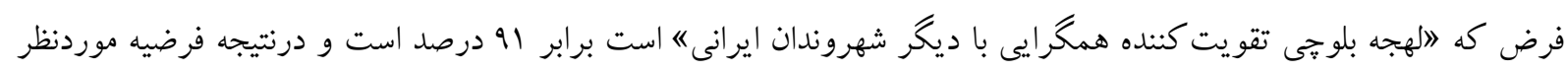
تائيد مىشود. 


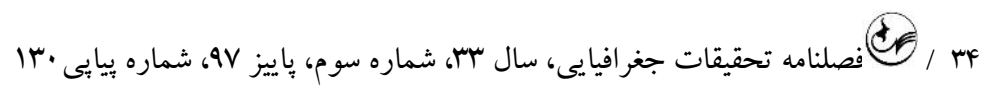
تأثير ساختار مذهبى بر كنش سياسى - اجتماعى شهروندان: با توجه به اينكه احتمال معنىدارى مشاهدهشده برابر أ . ٪ است

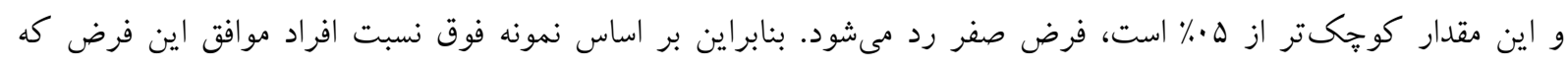

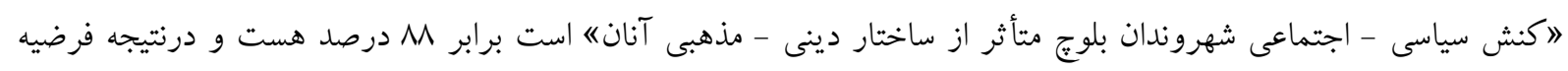
موردنظر تائيد مىشود.

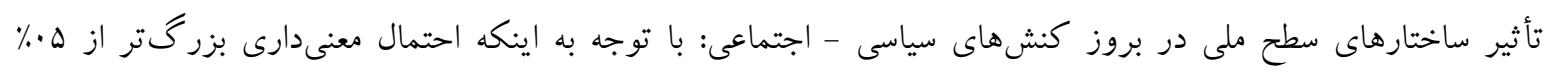

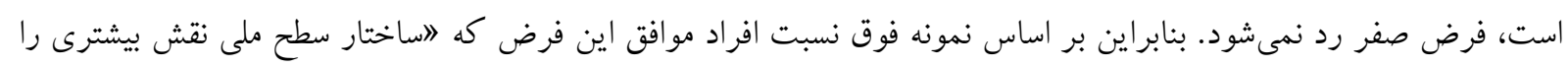

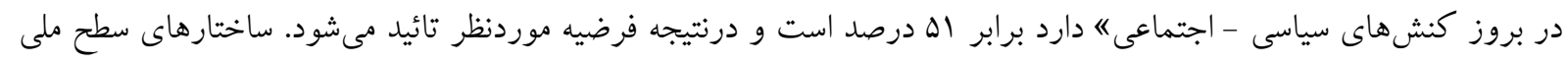

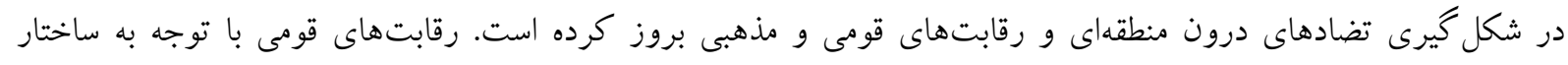

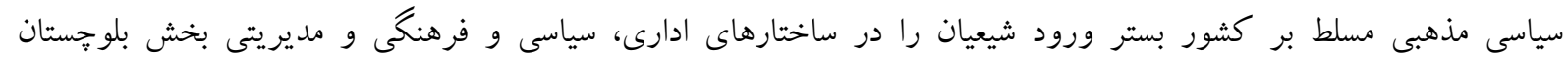

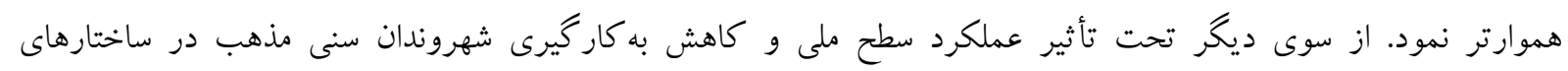

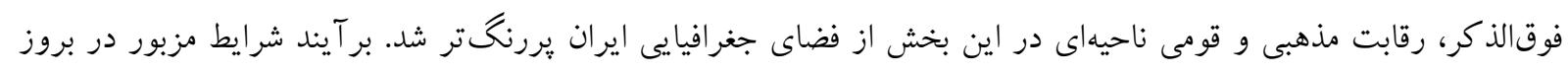
جالشها و منازعات محلى بى تأثير نبود.

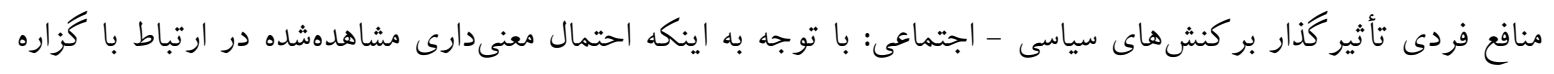

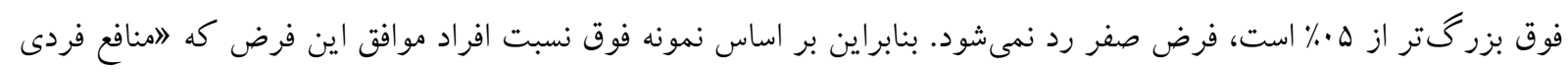

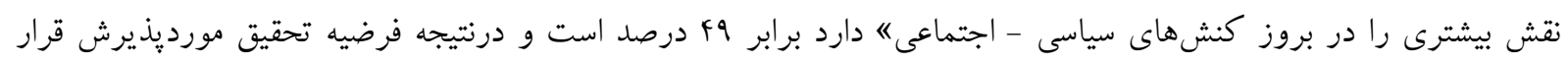
نمى كيرد.

\section{نتيجه كيرى}

بررسى خصلتها، ويزگى ها، روحيات، ارزشها، ايستارها و احساسات شهروندان بلوج در متغيرهاى موردمطالعه، نشان

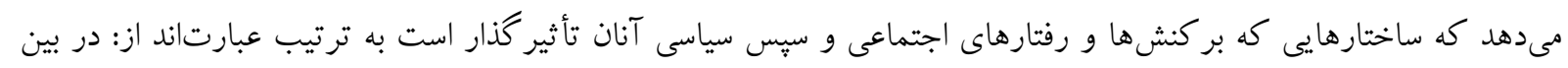

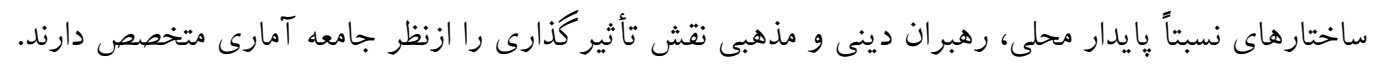
جدول ب- متغير هاى اجتماعى - فرهنكى تأثير كذار

\begin{tabular}{|c|c|}
\hline \multicolumn{2}{|c|}{ بر كنش سياسى شهروندان بلوج } \\
\hline رتبه & شاخصها \\
\hline 1 & رهبرى دينى و مذهبى \\
\hline r & زبان بلوجى \\
\hline r & آيين ها و رسمهاى محلى \\
\hline f & ساختار طايفهاى \\
\hline$\Delta$ & 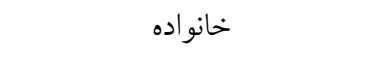 \\
\hline s & فرد بهعنوان عضوى از قوم بلوج \\
\hline v & شبكه هاى اجتماعى نوين \\
\hline$\wedge$ & رسانههاى دولتى \\
\hline 9 & منافع فردى \\
\hline 1. & ساختار سطح ملى \\
\hline
\end{tabular}

در ارتباط با نظر شهروندان بلوج، نتايج بهدست آمده در هر يك از متغيرهاى موردسنجش برابرى و شباهت زيادى به نظر

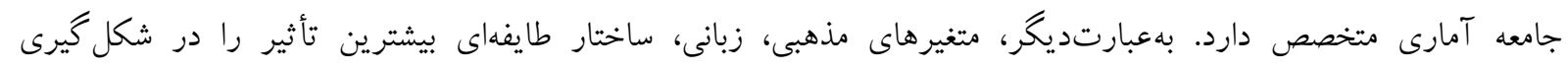


كنشهاى اجتماعى - سياسى شهروندان بلوج داشت. از سوى ديخر منافع فردى، رسانهاى دولتى و ساختار سطح ملى كمترين

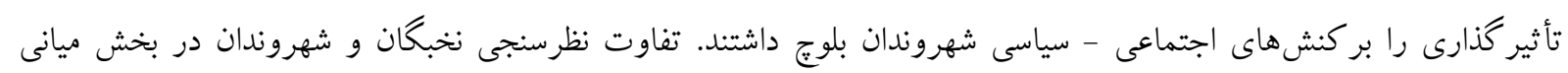

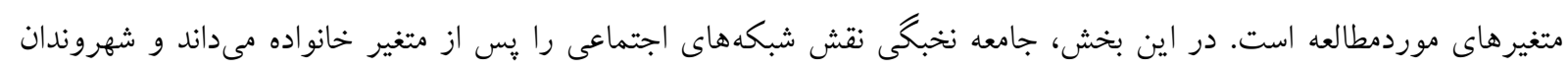
بلوج، نقش شبكههاى اجتماعى را يررنخ تر مى مدانند.

\begin{tabular}{|c|c|c|}
\hline مخالف & موافق & متغيرها \\
\hline r & Fr & رهبرى دينى و مذهبى \\
\hline$a$ & re & تأثير ساختار مذهبى \\
\hline r & Fr & زبان بلوجى \\
\hline r & ro & آيينها و رسمهاى محلى \\
\hline r & Fr & ساختار طايفهاى \\
\hline r & rv & خانو اده \\
\hline r & r & قوم محور بودن كنشها \\
\hline r & f. & شبكههاى اجتماعى نوين \\
\hline IV & 11 & رسانههاى دولتى \\
\hline 1. & rq & منافع فردى \\
\hline r & rq & سطح ملى(منافع ملى) \\
\hline r. & M & ساختار سطح ملى \\
\hline r & rV & كليت فرهنگ حاكم \\
\hline f & f. & تأثير لهجه بر همخرايى ملى \\
\hline
\end{tabular}

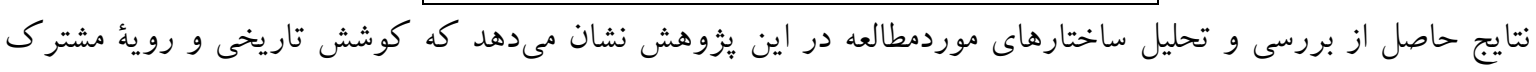

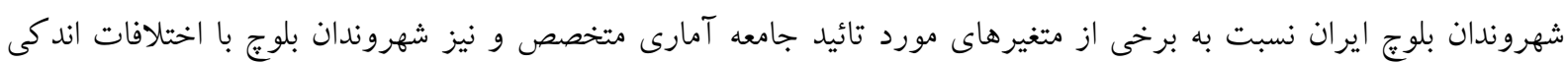
شبيه يكديخر است. در بين متغيرهاى بررسى آشده، نقش رهبران دينى و مذهبى بيش از ساير متغيرها است. اعتقادات مذهبى نقش بسزايى در

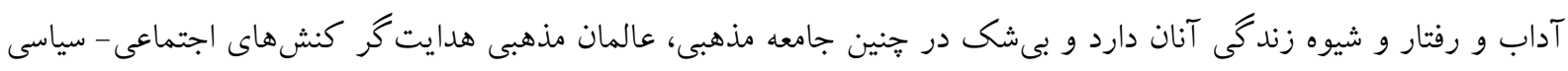

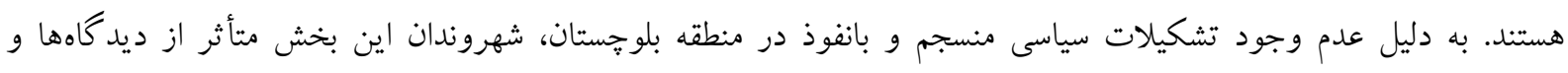

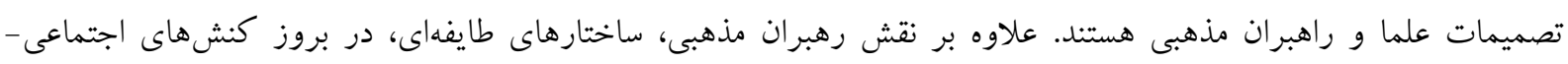

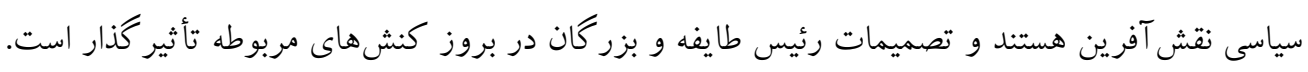

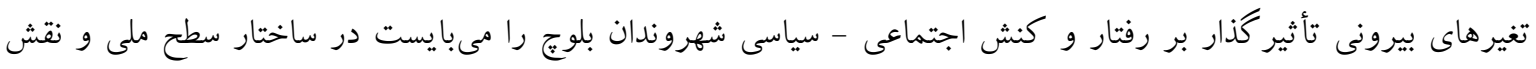

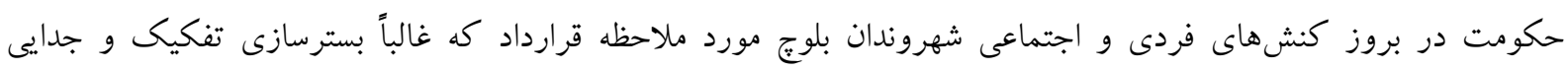

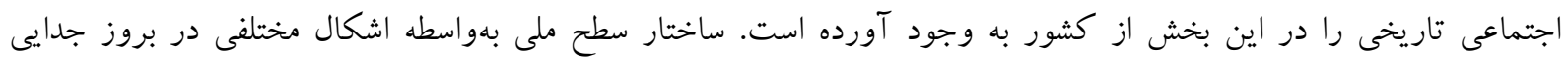

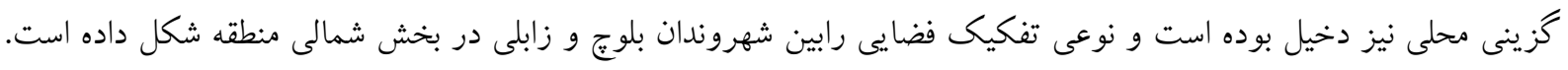

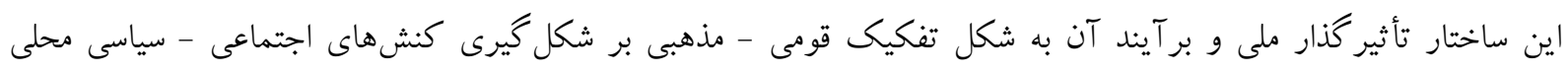

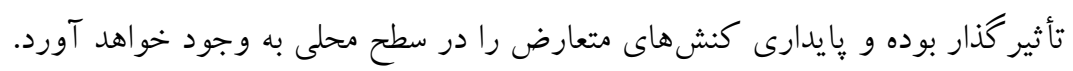




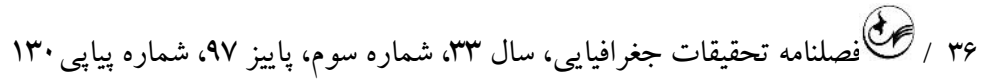

$$
\begin{aligned}
& \text { سهم نويسند گان: برزين ضرغامى (نويسنده اول)،يزوهشخر اصلى ( •ه٪)، ابراهيم رومينا (نويسنده دوم،مسئول)، ( •ه٪). }
\end{aligned}
$$

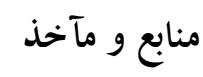

Ahmadi, H. (2004). Ethnicity \& ethnocentrism in Iran: myth \& reality (4 ed.). Tehran: Nashreney. (Persian)

Almond, G. (1956). Comparative political systems. Journal of Politics, 18(3), 391-409. [DOI:10.2307/2127255]

Almond, G., \& Coleman, J. (Eds.). (1960). The politics of the developing areas. Princeton, NJ: Princeton University Press.

Azad Armaki, T. (1997). Theories of sociology. Tehran: Soroush. (Persian)

Azkia, M., \& Ghaffari, G. (2005). Development sociology. Tehran: Keyhan. (Persian)

Bashiriyeh, H. (2005). Marxist thoughts (Sixth ed.). Tehran: Ney. (Persian)

Bashiriyeh, H. (2010). Political sociology. Tehran: Ney. (Persian)

Chilcote, R. H. (1998). Theories of comparative politics (V. Bozorgi \& A. R. Teyeb, Trans.). Tehran: Rasa. (Persian)

Craib, I. (2002). Modern social theory from parsons to habermas (A. Mokhber, Trans.). Tehran: Agah. (Persian)

Dalby, S. (2008). Imperialism, domination, culture: The continued relevance of critical geopolitics. Geopolitics, 13(3), 413-436. [DOI:10.1080/14650040802203679]

Dowse, R. E., \& Hughes, J. A. (1972). Political sociology. New York: John Wiley and Sons Ltd.

Ebrahimbai Salami, G. H. (2005). The perspective of sustainable development in eastern Iran. Geographical Researches Quarterly Journal, 20(2), 46-65. (Persian)

Ebrahimzadeh, I. (2010). Land use and environmental planning in South East of Iran. Tehran: Ettelaat. (Persian)

Ebrahimzadeh, I. (2012). Geographical area of southeast of Iran with emphasis on Sistan and Baluchestan. Tehran: Samt. (Persian)

Eckstein, H. (1988). A culturist theory of political change. American Political Science Association, 82(3), 789804. [DOI:10.2307/1962491]

Ghalibaf, M. B. (1996). Investigating of geographic elements in the security of Sistan and Baluchestan. (Master's thesis), Tehran University. (Persian)

Hafeznia, M. R., \& Allahverdizade, R. (2010). A Study of Relationship between the Unitary State System and National Unity: Case Study of Iran. Iranian Political Science Association, 5(1), 41-68. (Persian)

Hafeznia, M. R., \& Kaviani Rad, M. (2004). The new approaches in political geography. Tehran: Samt. (Persian)

Hajiani, E. (2010). Rreviewof cultural problems. Tehran: Expediency Discernment Council. (Persian)

Hatch, M. J. (1997). Organization theory: Modern, symbolic and postmodern perspectives. London: Oxford University Press.

Hosseini, S. S. (2008). Government policy and interethnic relations (Case: Baluch and Sistani). (Master's Thesis), Tarbiat Modares University. (Persian)

Inglehart, R. (1988). The renaissance of political culture. The American Political Science Review, 82(4), 12031230. [DOI:10.2307/1961756]

Janebollahi, M. S. (1996). Political, social and economic systems in Baluch Sarhad Tribes (case study: Riggi Tribe). Geographical Researches Quarterly Journal, 41, 59-82. (Persian)

Karimipour, Y. (1992). Geopolitical analysis of crisis areas of Sistan and Baluchestan. (PhD thesis ), Tarbiat Modares University. (Persian)

Kaviani Rad, M. (2001). The role of ethnic identity in national unity (case: Baluch ethnic). (Master's thesis), Tarbiat Modarres University. (Persian)

Lashgari Tafreshi, E. (2018). An inquiry into the recognition of spatial contexts of centralization governance system acceptability in Iran's political culture in recent century. Geographical Researches Quarterly Journal, 33(1), 224-237. [DOI:10.29252/geores.33.1.224]. (Persian)

Lazarsfeld, P. F. (1997). Insights and important trends in contemporary sociology (G. A. Tavassoli, Trans.). Tehran: Amirkabir. (Persian)

Lerner, D., \& Lucille, W. (2004). The passing of traditional society: modernizing the middle east (G. R. Khajeh Sarvi, Trans.). Tehran: Research Institude of Strategic Studies. (Persian)

Lijphart, A. (1980). The structure of inference, in gabriel almond and sydney verba, The Civic Culture Revisited.

Maghsoudi, M. (2001). Ethnic evolution in Iran, causes and contexts. Tehran: National Studies Institute.(Persian)

Mirmohammadi, D. (2004). Discourses on national identity in Iran. Tehran: National Studies Institute. (Persian) 
تأثير ساختارهاى محلى بر كنش اجتماعى - سياسى مورد: بلوجهاى ايران /

Moghadasi, A. A., \& Ghodrati, H. (2004). The anthony giddens structural theory and its methodological foundations. Journal of Social Sciences, Ferdowsi University, 1(4), 1-31. (Persian) [DOI:10.22067/jss.v0i0.3086]

Nosratinejad, F. (2002). A survey on the political culture of political groups. (Thesis, MSc), Tarbiat Modarres University of Tehran. (Persian)

Papoli Yazdi, M. H. (1988). Political-economic effects of Balochistan without palm trees. Geographical Researches Quarterly Journal, 4(2), 5-35. (Persian)

Razzaghi, S. (1996). Components of our political culture. Naghd va Nazar, 2(7-8), 200-213. (Persian)

Rezaei, M. (2015). Impact of regional demands on political action, case: Baluch. (Master's Thesis), Tarbiat Modares University. (Persian)

Ritzer, G. (1998). Contemporary sociological theory (M. Salasi, Trans.). Tehran: Elmifarhangi. (Persian)

Salzman, P. C. (1996). Kin and contract in Baluchi herding camps (M. Daneshvar, Trans.). Zahedan: Plan and Budget Organization. (Persian)

Sariolghalam, M. (2010). Political culture of Iran. Tehran: Institute for Social and Cultural Studies. (Persian)

Weiner, M., \& Huntington, S. (2002). Understanding political development, translated: Research Institude of Strategic studies (Research Institude of Strategic Studies, Trans.). Tehran: Research Institude of Strategic Studies. (Persian)

Zarghami, B. (2010). Comparative analysis of the opportunistic and threatening geopolitical backgrounds of Baluch and Turkman in Iran. (PhD Thesis), University of Tehran. (Persian) 